\title{
Klotho Protein Measurement
}

National Cancer Institute

\section{Source}

National Cancer Institute. Klotho Protein Measurement. NCI Thesaurus. Code C127624.

The determination of the amount of klotho protein present in a sample. 